\title{
Uma metodologia para a seleção de um provedor de serviços logísticos
}

\author{
Maurício Mengai Iañez \\ Cláudio Barbieri da Cunha \\ Programa de Pós-Graduação em Engenharia de Transportes, Escola Politécnica da USP
}

\begin{abstract}
Resumo
Este artigo trata do problema da tomada de decisão de terceirização das atividades logísticas e da seleção de um provedor de serviços logísticos. Propõe-se uma metodologia que compreende, basicamente, três aspectos principais: a análise e a compreensão das oportunidades e riscos relacionados à terceirização das atividades logísticas; a proposição de atributos importantes que podem ser considerados no processo decisório; o auxílio às empresas na avaliação das diferentes alternativas de provedores de serviços logísticos e seleção da opção mais adequada, de acordo com as suas necessidades e expectativas. A metodologia proposta baseia-se no Método de Análise Hierárquica (MAH), que permite tratar aspectos quantitativos e qualitativos, tendo sido aplicado a inúmeros problemas que envolvem a tomada de decisão em segmentos distintos.
\end{abstract}

Palavras-chave

Tomada de decisão, logística, terceirização.

\section{An approach for selecting a logistics service provider}

\begin{abstract}
This paper deals with the problem of the decision-making process related to outsourcing logistics activities and selecting a logistics service provider as well. The proposed approach comprises three main aspects: analyzing and understanding the opportunities and the risks involved in outsourcing logistics activities; proposition of a list of relevant attributes that should be considered in this decision process; and supporting companies needs in accessing the various alternatives and choosing the best alternative, which best fits the contractors needs. The proposed methodology is based on the Analytic Hierarchy Process (AHP], which allows qualitative and quantitative attributes to be considered, and has been applied to several decision-making processes in different segments.
\end{abstract}

Key words

Decision process, logistics, outsourcing. 


\section{INTRODUĈ̣̃O}

A globalização dos mercados e o surgimento de novas tecnologias, ocorridos ao longo das décadas de 80 e 90, alteraram substancialmente os padrões de competição dos negócios, em âmbito mundial. O decorrente acirramento da competição em mercados cada vez mais globalizados tem levado as empresas a iniciativas de reestruturação em busca de maiores níveis de qualidade e produtividade e de redução de custos.

Entre essas iniciativas, podem-se citar: a redução de custos; a elevação da qualidade dos serviços aos clientes; novas localizações para instalações, de forma a aumentar o alcance da distribuição e possibilitar atingir novos mercados; as novas alternativas para fontes de matérias-primas e de serviços; o foco nas competências principais; o enxugamento e a flexibilização de estruturas organizacionais, com a eliminação de ineficiências e duplicidade de atividades, entre outras. As empresas buscaram ainda estabelecer relacionamentos externos de longo prazo, do tipo ganha-ganha, visando benefício mútuo, através de alianças e parcerias com outras empresas.

Entretanto, observa-se que, de maneira geral, a grande maioria das empresas tem encontrado dificuldades para solucionar os problemas logísticos decorrentes dessa nova realidade, a saber, operações logísticas mais complexas e também mais importantes para as empresas, do ponto de vista estratégico, com o agravante de que essa solução normalmente não é uma competência principal dessas empresas. Em decorrência, vêm-se observando o florescimento e o desenvolvimento de um mercado de empresas especializadas em prover serviços logísticos, os chamados provedores de serviços logísticos.

No presente artigo, o termo provedor de serviços logísticos é utilizado no lugar de operador logístico, pois, de acordo com as definições encontradas na literatura por Iañez (2002), o mesmo deve ser especializado em integrar, planejar, gerenciar e executar todas ou parte das atividades logísticas nos diferentes elos que compõem a cadeia de suprimentos nas quais estão inseridos seus clientes. Tais atividades, segundo Bowersox e Closs (1996) e Ballou (1998), podem englobar, entre outras, o projeto da rede logística, o posicionamento estratégico e a gestão de estoques, o transporte, a armazenagem e o manuseio de materiais, o gerenciamento de informações logísticas, compras, suporte aos serviços de assistência técnica, a logística reversa, a reciclagem e a destruição de produtos.

Assim, entende-se que o uso do termo operador logístico poderia confundir o leitor, pois sugere apenas a sua capacidade operacional para execução dos serviços, não enfatizando também a sua desejável capacidade de integração, planejamento e gerenciamento das atividades logísticas, as quais compõem a cadeia de suprimentos de seus clientes.

Segundo Lieb e Miller (2000), a globalização dos mercados é uma tendência de organização econômica que favorece a expansão do mercado de provedores de serviços logísticos. Seus resultados apontaram que, devido à dificuldade de as empresas se adaptarem a mercados com características distintas, $69 \%$ das empresas participantes de suas pesquisas utilizavam os serviços de pelo menos um provedor de serviços logísticos para o planejamento, o gerenciamento ou a operação de suas atividades logísticas internacionais. Adicionalmente, a necessidade de aporte de capital para investimentos e a incidência de custos fixos operacionais podem tornar o projeto economicamente inviável, caso a empresa opte por iniciar por si própria a sua operação em determinado país; por outro lado, uma parceria com um provedor de serviços logísticos pode viabilizar a operação, caso este possa agregar à operação da empresa toda o volume/escala que já possui decorrente de operações com outros clientes.

\section{artigo trata do problema da tomada de decisão de terceirização logística e seleção de um provedor de serviços logísticos.}

Em muitas empresas, a terceirização das atividades logísticas tem sido adotada apenas em função dos custos e para atividades que possuam um risco de falha percebido relativamente baixo (por exemplo, na armazenagem). Já outras empresas têm terceirizado um número maior de atividades logísticas (por exemplo, gestão de estoques, separação de pedidos, gerenciamento de transporte, entre outras), obtendo considerável redução de custos logísticos, bem como ganhos potenciais de foco em suas atividades principais.

A flexibilidade proporcionada pela parceria com um provedor de serviços logísticos é um outro benefício que motiva as empresas a terceirizarem suas atividades logísticas. Segundo Lynch (2000), devido à velocidade com que novos mercados e novos produtos são desenvolvidos fica difícil para as empresas preverem suas necessidades logísticas futuras. Já os provedores de serviços logísticos, por atuarem para diversos clientes, e por necessitarem atualizar continuamente sua infra-estrutura, suas tecnologias e seus recursos humanos, têm flexibilidade para oferecer e viabilizar soluções logísticas modernas e customizadas segundo as necessidades específicas de seus clientes, aproveitando a experiência acumulada na operação de um determinado cliente em outros com necessidades e características similares. Assim, uma empresa, através da parceria com um pro- 
vedor de serviços logísticos, pode ter acesso, dessa forma, às soluções mais adequadas para atendimento do seu mercado, contemplando-se ainda as características e especificidades de seus diversos produtos.

Nesse contexto, o presente artigo trata do processo de decisão de terceirização de atividades logísticas, em especial do processo de decisão de seleção de um provedor de serviços logísticos. A metodologia proposta baseia-se no MAH - Método de Análise Hierárquica (também conhecido como AHP - Analytic Hierarchy Process), o qual vem sendo aplicado a inúmeros problemas que envolvem a tomada de decisão em segmentos distintos (por exemplo, alocação de energia, investimentos em tecnologias de retorno incerto, priorização na alocação de recursos escassos, resolução de conflitos políticos, entre outros).

Este trabalho está organizado da seguinte forma: a próxima seção aborda sucintamente o mercado de provedores de serviços logísticos; em seguida, apresenta-se uma revisão bibliográfica do problema da seleção de um provedor de serviços logísticos, seguindo-se uma descrição sumária do $\mathrm{MAH}$, e o detalhamento da metodologia proposta para auxílio às empresas na tomada de decisão de terceirização de suas atividades logísticas e seleção de um provedor de serviços logísticos. Nas duas últimas seções são apresentados os resultados da aplicação da metodologia a um estudo de caso real e as principais conclusões e recomendações do estudo.

\section{O MERCADO DE PROVEDORES DE SERVIC̣OS LOGÍSTICOS}

De acordo com Lynch (2000) e também Fleury (2000), os provedores de serviços logísticos podem ser divididos em dois grupos: (i) aqueles cuja operação está baseada em ativos, ou seja, focados em investimentos próprios em ativos fixos, sendo a solidez operacional sua maior vantagem; (ii) os provedores cuja operação baseia-se em informação e gestão, centralizando e responsabilizandose pela integração dos serviços de terceiros, sendo, neste caso, o efetivo produto ofertado a capacidade de planejamento, gerenciamento de processos, sistemas de informação e capacidade analítica, que lhes permite identificar e implementar as melhores soluções para cada cliente, com base na utilização de ativos de terceiros; nesse caso, a vantagem destacada é a flexibilidade na busca da melhor solução para cada cliente. Entretanto, os autores destacam não existir consenso ou unanimidade quanto a qual grupo de provedores de serviços logísticos é o melhor, o que depende da análise das necessidades individuais de cada cliente, do setor de atuação, do posicionamento no mercado, entre outros.

Quanto à sua origem, Fleury (2000) destaca que são duas as principais raízes para o surgimento dos provedores de serviços logísticos: (i) ampliação de serviços, isto é, empresas especializadas em transporte ou armazenagem, que, mediante parcerias ou aquisições, ampliam sua atuação; (ii) diversificação de atividades, ou seja, empresas industriais ou comerciais que, por terem desenvolvido alta competência para o gerenciamento interno de suas atividades logísticas, decidem diversificar o seu foco de atuação criando uma empresa específica para prestação de serviços logísticos integrados para terceiros. Como exemplo desta última pode-se citar a DDF, inicialmente uma divisão de logística do grupo Philips no Brasil, que depois se tornou uma empresa, prestando serviços para outras empresas do setor, sendo posteriormente adquirida pela Danzas Logística.

A evolução dos sistemas de informação foi decisiva para a evolução da terceirização das atividades logísticas, já que possibilitou e facilitou o intercâmbio e o compartilhamento das informações necessárias para viabilizar o fluxo eficiente de operações entre os diversos agentes de uma cadeia de suprimentos, permitindo reduzir os lead-times nas operações com parceiros, aumentar a confiabilidade e a segurança dos dados trocados, além de as empresas poderem ter um acompanhamento mais próximo das atividades realizadas pelos provedores de serviços logísticos.

Quanto às atividades logísticas terceirizadas, a média por empresa cresceu de 1,5 em 1989 para 5,5 em 1994, segundo Bowersox e Closs (1996). De acordo com Lieb e Randall (1996), mais de 60\% das 500 maiores empresas da revista Fortune revelaram que tinham pelo menos um contrato com um provedor de serviços logísticos. Segundo Boyson et al. (1999), 19\% das empresas indicavam que não terceirizavam nenhuma atividade logística, 23,5\% indicavam que estavam terceirizando pelo menos uma atividade logística e 9,9\% citavam que toda a cadeia de suprimentos era terceirizada.

De acordo com Lieb e Miller (2000), 77\% das empresas estavam utilizando os serviços de um provedor de serviços logísticos, 15\% afirmaram que estavam trabalhando com provedores de serviços logísticos há mais de cinco anos, despendendo em média 19\% do seu orçamento logístico com este tipo de fornecedor. Os autores verificaram ainda que em $73 \%$ dos casos as empresas estavam utilizando mais de um provedor de serviços logísticos.

Esta é uma mudança significativa, dado que o percentual de empresas que têm trabalhado com múltiplos provedores de serviços logísticos caiu significativamente entre os anos de 1991 e 1998, de 79\% para apenas 40\%. Para os autores, esta é uma conseqüência da demanda por serviços, que em muitas empresas é tão elevada que apenas um único provedor de serviços logísticos não consegue preencher todos os requisitos exigidos.

Segundo Hoffman (2000), esta tendência de se utilizar mais de um provedor de serviços logísticos levou ao desenvolvimento de uma prática européia conhecida como Lead 
Logistics Provider ( $L L P$ ou $4 P L$ ), segundo a qual um dos provedores de serviços logísticos é selecionado para gerenciar o relacionamento e coordenar a operação integrada de outros provedores de serviços logísticos. Outro movimento observado por Lieb e Miller (2000) é a globalização dos provedores de serviços logísticos; em sua pesquisa, $69 \%$ dos usuários responderam que estavam utilizando os serviços do provedor em suas atividades internacionais.

Por outro lado, não existe um consenso ou unanimidade quanto aos resultados dessas parcerias logísticas. Para muitas empresas a terceirização logística é vista como uma solução para uma rápida expansão de mercado, assim como para a redução de custos do sistema logístico e para o incremento de vantagens competitivas e da qualidade dos serviços prestados aos seus clientes. Lieb et al. (1993) reportam que algumas empresas alcançaram 30\% a 40\% de redução nos seus custos logísticos e ainda foram capazes de desenvolver processos logísticos globais e de maior qualidade como conseqüência da terceirização de suas atividades logísticas.

Ackerman (1996) e Gulisano (1997) descrevem casos em que a terceirização das atividades logísticas tornou-se uma fonte de insatisfação e de falhas corporativas. É importante destacar que os insucessos têm sido geralmente atribuídos principalmente a deficiências no processo decisório de avaliação e seleção do provedor de serviços logísticos; adicionalmente, podem-se citar outros aspectos, tais como objetivos obscuros e expectativas irrealistas do processo de terceirização, falta de informações adequadas durante o desenvolvimento do projeto, falta de comprometimento de alguns funcionários das empresas que terceirizaram suas atividades logísticas e falhas nos contratos entre a empresa $\mathrm{e}$ o provedor de serviços logísticos. Todos esses fatores tornam o processo de terceirização de atividades logísticas e seleção

do provedor de serviços logísticos uma das decisões mais complexas para uma empresa, e enfatizam a importância da metodologia proposta neste trabalho.

Adicionalmente, inúmeros atributos que influenciam este processo decisório, tais como infra-estrutura, estabilidade financeira, credibilidade, experiência, gestão da qualidade, recursos humanos, tecnologia, eficiência operacional e custo baixo, entre outros, geralmente são difíceis de ser encontrados em um único provedor de serviços logísticos, como destacam Bowman,1997), Sink e Langley (1997) e Lynch (2000). Um outro aspecto que dificulta a análise e a decisão é a existência de atributos quantitativos (por exemplo: estabilidade financeira e custo), e outros qualitativos (por exemplo: credibilidade, experiência, gestão da qualidade), os quais precisam ser comparados no processo decisório.
Assim, uma contribuição para a melhoria desse processo, objeto deste trabalho, corresponde à proposição de uma metodologia para auxílio às empresas na tomada de decisão de terceirização de suas atividades logísticas e seleção de um provedor de serviços logísticos, que permita avaliar os atributos quantitativos e os atributos qualitativos considerados importantes para esta tomada de decisão.

\section{O PROCESSO DE SELECÃO DE UM PROVEDOR DE SERVICOOS LOGÍSTICOS}

Iañez (2002) procurou realizar uma ampla análise das questões que envolvem a seleção de um provedor de serviços logísticos. Partindo da conceituação do provedor de serviços logísticos, discutiram-se suas possíveis origens, caracterizaram-se os tipos de provedores de serviços logísticos presentes no mercado e as atividades logísticas que o mesmo deve estar apto a desenvolver. Foram também contemplados os aspectos mais relevantes dos mercados internacional e nacional de provedores de serviços logísticos.

O processo de terceirização das atividades logísticas foi amplamente discutido, concluindo-se que o mesmo é composto por diversas etapas, sendo bastante complexo. Uma das etapas mais difíceis deste processo decisório é a etapa que corresponde à avaliação das alternativas de provedores de serviços logísticos disponíveis e a seleção da melhor alternativa, a qual deve ser feita através da análise dos atributos quantitativos e qualitativos mais importantes para este processo decisório.

\section{proposta uma metodologia baseada no Método de Análise Hierárquica (MAH), que permite tratar aspectos quantitativos e qualitativos.}

Foram revisadas e avaliadas as principais metodologias para análise do problema de seleção de um provedor de serviços logísticos, à luz dos principais conceitos apresentados na literatura, sendo identificados os chamados métodos multiobjetivos, ou seja, que permitem considerar concomitantemente múltiplos objetivos, como os mais adequados para auxílio à resolução deste tipo de problema. Além disto, Iañez (2002) discutiu os atributos citados na literatura como os mais importantes para a análise de alternativas de provedores de serviços logísticos, uma vez que, neste tipo de problema de tomada de decisão, não existe uma solução ótima, devendo o tomador de decisão estar apto a avaliar os diversos trade-offs existentes e selecionar a melhor alternativa disponível. Segundo Vincke (1992), o que deve ser notado quando se está lidando com este tipo de problema é que não 
existe, em geral, nenhuma decisão que é simultaneamente ótima sob todos os pontos de vista e atributos.

A partir do final da década de 70 e início da década de 80, os métodos multiobjetivos de auxílio à tomada de decisão passaram a receber crescente atenção por parte dos especialistas em questões decisórias, especialmente nos casos que envolviam conflitos de interesse.

Neste ponto vale salientar que a bibliografia especializada não utiliza uma nomenclatura única para referenciar este tipo de métodos de seleção. Alguns autores os nomeiam de métodos multiobjetivos e outros de métodos multicritérios. A partir da leitura e interpretação destas diversas bibliografias, conclui-se que ambas as nomenclaturas podem ser utilizadas, uma vez que os métodos propostos têm como característica avaliar os diversos objetivos importantes para a tomada de decisão, sendo, portanto, métodos multiobjetivos, assim como considerar os diferentes pontos de vista dos diversos tomadores de decisão, sendo, portanto, métodos multicritérios. considerar simultaneamente atributos quantitativos e qualitativos em sua análise, ao mesmo tempo em que incorpora a experiência e a preferência dos tomadores de decisão; (iii) o resultado final permite definir uma seqüência cardinal ${ }^{1}$ da importância dos atributos e das alternativas; (iv) aplicável a questões complexas, que envolvam julgamentos subjetivos. É capaz de lidar e absorver julgamentos inconsistentes dos tomadores de decisão, incentivando assim a discussão e a reavaliação do problema.

A característica principal que distingue o MAH diz respeito à forma com que a técnica define o problema a ser analisado. A premissa básica do MAH é que o sistema decisório complexo deve ser definido segundo uma estrutura hierárquica composta de vários níveis, que compreendem os elementos cujas características podem ser consideradas similares. Esse tipo de estruturação do problema é bastante adequada, uma vez que permite uma visão bastante ampla de todo o sistema e possibilita que as influências entre os diversos elementos do problema sejam facilmente identificadas, especialmente nos casos em que o objetivo do sistema decisório consiste na seleção de alternativas segundo múltiplos atributos.

Segundo Saaty (1980), a grande vantagem do MAH é permitir aos seus usuários atribuir pesos relativos para múltiplos atributos, ou múltiplas alternativas para um dado atributo,

O trabalho de Roy (1977), apud Caixeta-Filho e Martins (2001), lançou as bases para a primeira metodologia efetivamente estruturada para a análise de alternativas com múltiplos objetivos, gerando a família de métodos ELECTRE (Elimination et Choix Traduissant la Realité).

Conforme observado em Saaty (1980), em 1977 foram publicados dois artigos referentes aos fundamentos conceituais do Método de Análise Hierárquica (MAH). O primeiro deles apresentava as bases axiomáticas da metodologia, e o segundo descrevia uma aplicação do MAH na elaboração do estudo de transporte de longo prazo para o Sudão. A principal característica desse método é a modelagem dos problemas decisórios segundo uma estrutura hierárquica.

Entre os métodos avaliados identificou-se o MAH - Método de Análise Hierárquica como o mais adequado para este tipo de tomada de decisão, cujos principais conceitos e características são apresentados na próxima seção.

\section{O MÉTODO DE ANÁLISE HIERÁRQUICA}

O MAH é um método multiobjetivo, desenvolvido pelo matemático Thomas Lorie Saaty, para auxílio à tomada de decisão, cujas principais características são (SAATY, 1980): (i) aplicável aos problemas orientados por múltiplos atributos ou objetivos estruturados hierarquicamente; (ii) capaz de ao mesmo tempo em que realiza uma comparação par a par entre os mesmos. Isso permite que, mesmo quando dois atributos são incompatíveis, a mente humana possa, ainda assim, reconher qual dos atributos é mais importante para o processo decisório.

Para Saaty (1980), os princípios básicos do pensamento analítico são: a estruturação hierárquica, a obtenção de prioridades e a consistência lógica. Essas três qualidades estão presentes no método MAH.

\section{Estruturação hierárquica}

Para aplicar o MAH, o tomador de decisões deve definir um objetivo global e selecionar os atributos e subatributos para atingir o objetivo. Todos os elementos deverão estar estruturados hierarquicamente, conforme apresentado na Figura 1.

A decomposição da estrutura do problema ajuda a lidar com a complexidade do processo. Assim, quanto mais genéricos forem os atributos, mais altos eles deverão estar na hierarquia. As alternativas ficam na base da árvore, abaixo do último nível de subatributos. Esse arranjo permite fazer com que seja possível para o tomador de decisão focalizar cada parte e todo o complexo problema, e com isso obter prioridades através de uma simples comparação par a par baseada nos dados obtidos pelo usuário, 
nos seus conhecimentos e na sua própria experiência. $\mathrm{Na}$ aplicação do método recomenda-se não utilizar mais do que nove atributos.

\section{Obtenção de prioridades}

Segundo Saaty (1980), com relação à obtenção de prioridades, os seres humanos também possuem facilidade para criar relações entre coisas. Eles observam e encontram similaridades, segundo um certo critério, e as discriminam das outras coisas, através de julgamentos de intensidade de preferência de uma em relação às outras. No MAH, estabelece-se uma relação entre cada nível de hierarquia pela comparação dos atributos ou subatributos aos pares. Essa relação representa o impacto relativo dos elementos de um dado nível em cada elemento do nível acima mais próximo.

Os valores possíveis de serem atribuídos para a comparação paritária entre os atributos relevantes para a decisão estão relacionados no Quadro 1.

\section{Consistência lógica}

O terceiro princípio do pensamento analítico é a consistência lógica. Nesse sentido, o ser humano tem a habilidade de estabelecer relações entre objetivos ou idéias, de tal forma a buscar uma coerência entre eles, ou seja, de relacioná-los entre si e dessa relação avaliar se ela possui consistência. Ao utilizar tais princípios, o MAH incorpora tanto aspectos qualitativos quanto quantitativos do pensamento humano: a qualidade para definir o problema, a sua hierarquia e os aspectos quantitativos para expressar julgamentos e preferências de forma concisa.

O conceito de consistência é estabelecido quando, dada uma quantidade de dados iniciais, todos os outros dados podem ser logicamente deduzidos a partir deles. Ao estabelecer a comparação paritária para relacionar $n$ atividades, de modo que cada uma seja representada nos dados pelo menos uma vez, precisamos de $n$ - 1 comparações paritárias.

Como consistência, Saaty (1980) não se refere à necessidade tradicional de transitividade de preferências, mas sim à intensidade real com a qual a preferência expressa transita ao longo da seqüência de objetos em comparação. Exemplificando, se a atividade $A_{1}$ é 3 vezes mais dominante do que a atividade $\mathrm{A}_{2}$, e a atividade $\mathrm{A}_{2}$ é 2 vezes mais dominante do que a atividade $A_{3}$, então $A_{1}=6 A_{3}$, portanto, dizemos que $o$ julgamento é consistente.

Inconsistência é uma violação da proporcionalidade que pode ou não significar violação da transitividade. $\mathrm{O}$ estudo de Saaty (1980) demonstra que o importante não é o caso de sermos inconsistentes em comparações específicas, mas quão fortemente a consistência é violada no sentido numérico para o estudo geral do problema. Os julgamentos raramente possuem uma relação simples e objetiva o que requer um cálculo de grau de consistência mais complexo. Segundo o autor, isto acontece freqüentemente e não é um grande problema. Para a maioria dos problemas é bastante difícil identificar $n-1$ julgamentos que relacionem todas as

Figura 1: Elementos básicos de uma estrutura hierárquica do MAH.

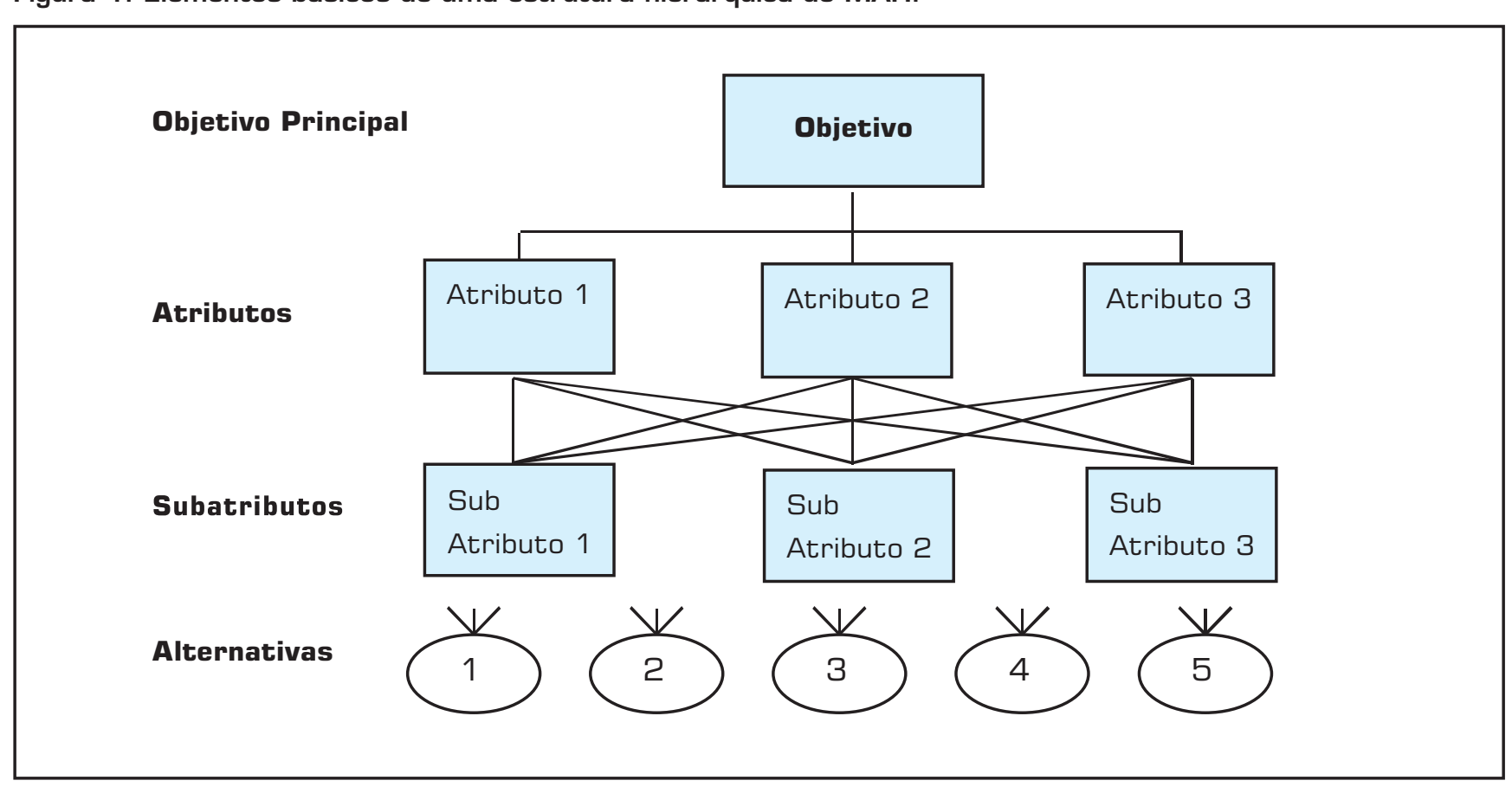


atividades e que permitam deduzir o relacionamento existente entre elas.

O MAH é um método de análise que considera e julga múltiplos atributos baseando-se na ótica subjetiva e naturalmente inconsistente de seres humanos, e em dados concretos obtidos do mundo real através de medições inexatas. O poder do método está em simplificar o trabalho da mente, através da ponderação de pares de elementos. Mas ao julgarmos dois elementos apenas, através de uma escala limitada a 9 graus de conceitos subjetivos de importância ou preferência, estreitamos nossa visão da realidade e nos concentramos em uma fração do problema, desconsiderando a influência do conjunto.

Ao estabelecermos a importância de dois elementos com relação a um terceiro na primeira linha da matriz, estaremos fazendo apenas uma primeira abordagem do problema, uma espécie de reconhecimento. Será com o preenchimento dos demais campos da matriz de comparações paritárias que os tomadores de decisão serão incentivados a reavaliar suas opiniões, ampliando sua visão do problema e compreendendo-o melhor. A presença de inconsistência nos julgamentos não significa uma falha do método, pelo contrário, ela é perfeitamente normal e útil, contanto que esteja sob controle.

Em síntese, a aplicação do método pode ser dividida em quatro etapas:

i) Estruturar os objetivos, atributos e alternativas em uma hierarquia.

ii) Obter os dados dos julgamentos comparativos de cada par dos fatores de decisão (atributos, subatributos e alternativas) em um dado nível do grupo. Existindo ainda a necessidade de verificação do nível de consistência dos julgamentos de cada grupo.
iii)Determinar as prioridades relativas dos pesos dos atributos de decisão, em cada nível ou grupo.

iv) Consolidar todos os pesos, propagando o efeito dos pesos na estrutura até o nível das alternativas. A recomendação da decisão é dada pela classificação das alternativas de decisão, ordenadas relativamente ao objetivo global.

Observa-se, portanto, que depois de concluído o processo de discussão entre os tomadores de decisão, quando todas as matrizes de comparações paritárias estiverem completas e respeitando os limites de inconsistência de julgamentos, passa-se à etapa final do método, estabelecendo a prioridade das alternativas.

\section{METODOLOGIA PARA AUXÍLIO À TOMADA DE DECISÃO DE TERCEIRIZAC̣ÃO DAS ATIVIDADES LOGISTICAS}

A metodologia proposta para auxílio às empresas na tomada de decisão de terceirização de suas atividades logísticas e seleção de um provedor de serviços logísticos é composta por quatro etapas e considera os conceitos do MAH para a estruturação do problema, a comparação das alternativas e a tomada de decisão.

Deve-se ter em mente que, neste processo decisório, o objetivo da empresa contratante é selecionar a melhor alternativa de provedor de serviços logísticos, de acordo com as suas características e necessidades, não necessariamente o provedor que ofereça, por exemplo, a maior flexibilidade de serviços logísticos, ou os menores custos, ou os melhores recursos humanos, mas sim o provedor que proporcione

Quadro 1: Fatores para as comparações paritárias.

\begin{tabular}{|c|l|l|}
\hline $\begin{array}{c}\text { INTENSIDADE DE } \\
\text { IMPORTÂNCIA }\end{array}$ & \multicolumn{1}{|c|}{ DEFINIÇÃo } & \multicolumn{1}{|c|}{ EXPLICAÇÃ̃o } \\
\hline 1 & Mesma importância & $\begin{array}{l}\text { Os dois atributos contribuem igualmente para } \\
\text { objetivo }\end{array}$ \\
\hline 3 & Importância pequena de um sobre o outro & $\begin{array}{l}\text { A experiência e o julgamento favorecem } \\
\text { levemente um atributo em relação ao outro }\end{array}$ \\
\hline 5 & Importância grande ou essencial & $\begin{array}{l}\text { A experiência e o julgamento favorecem } \\
\text { fortemente um atributo em relação ao outro }\end{array}$ \\
\hline 7 & Importância muito grande ou demonstrada & $\begin{array}{l}\text { Um atributo é fortemente favorecido em relação } \\
\text { ao outro; sua dominação de importância é } \\
\text { demonstrada na prática }\end{array}$ \\
\hline 9 & Importância absoluta & $\begin{array}{l}\text { A evidência favorece um atributo em relação ao } \\
\text { outro com o mais alto grau de certeza }\end{array}$ \\
\hline $2,4,6,8$ & $\begin{array}{l}\text { Valores intermediários entre os valores } \\
\text { adjacentes }\end{array}$ & $\begin{array}{l}\text { Quando se procura uma condição de } \\
\text { compromisso entre duas definições }\end{array}$ \\
\hline
\end{tabular}

Fonte: Saaty (1980) 
a melhor relação entre os diversos atributos e subatributos relevantes para a tomada de decisão.

Apresenta-se, no Quadro 2, uma proposta de atributos e subatributos relevantes para a seleção de um provedor de serviços logísticos. Cabe notar que não se tem a intenção de identificar e relacionar todos os atributos e subatributos importantes para a seleção de um provedor de serviços logísticos, mas sim alertar para a importância de se considerar outros atributos menos quantitativos, os quais são importantes para a avaliação das alternativas. A definição da relação de atributos é específica do processo decisório realizado em cada empresa, podendo apresentar variações de acordo com os objetivos que direcionam sua decisão.

A metodologia proposta para auxílio às empresas no processo decisório de terceirização de suas atividades logísticas e seleção de um provedor de serviços logísticos pode ser estruturada em quatro etapas: (i) compreender as oportunidades e os riscos com a terceirização das atividades logísticas; (ii) identificar as necessidades da cadeia de suprimentos da empresa; (iii) desenvolver alternativas de provedores de serviços logísticos; (iv) avaliar as alternativas de provedores de serviços logísticos e a alternativa interna para a tomada de decisão. Cada uma das etapas é detalhada a seguir.

- Compreender as oportunidades e os riscos da terceirização das atividades logísticas

Como uma primeira etapa do processo de terceirização das atividades logísticas é importante que a empresa procure compreender as oportunidades e riscos que envolvem a decisão de terceirização de suas atividades logísticas.

Essa compreensão das oportunidades e riscos que envolvem a decisão de terceirização de suas atividades logísticas é composta pelo entendimento do novo ambiente de negócios, o entendimento dos conceitos e capacitações de um provedor de serviços logísticos, uma auto-avaliação da empresa, verificando se a mesma está pronta para a terceirização, como também a obtenção do comprometimento da alta administração, conforme indicado na Figura 2.

\section{- Identificar as necessidades logísticas da empresa}

Na segunda etapa da metodologia proposta (Figura 3), a empresa deve ser capaz de identificar as suas necessidades logísticas, ou seja, deverá formar uma equipe multidisciplinar, desenhar sua cadeia de suprimentos, identificar oportunidades de melhoria e custos para viabilizar a solução interna, além de definir os objetivos a serem alcançados com a terceirização.

\section{- Desenvolver as alternativas de provedores de serviços logísticos}

Esta etapa compreende a definição dos atributos para a avaliação, a geração das alternativas, o envio da $R F I$ (Request for Information) e a pré-qualificação dos provedores, conforme mostrado na Figura 4.

Figura 2: Atividades que compõem a etapa de compreensão das oportunidades e os riscos com a terceirização das atividades logísticas.

\section{Entender o novo ambiente de negócios}

$\checkmark$ Globalização dos mercados

$\checkmark$ Ampliação da competitividade dos mercados Foco das empresas em suas atividades principais Busca por maior flexibilidade

Melhor taxa de retorno sobre o investimento

Reduzir custos logísticos

Transformar custos fixos em variáveis

Obter acesso às novas tecnologias

$\checkmark$ Desenvolvimento dos sistemas de informação

$\checkmark$ Desenvolvimento da internet e do comércio eletrônico

\section{Comprometimento}

$\checkmark$ Obter o comprometimento da alta administração para a análise da terceirização

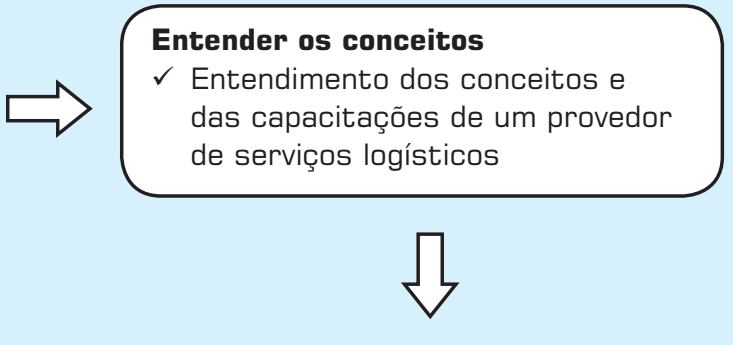

Auto-avaliação

$\checkmark$ A empresa está preparada para:

$\checkmark$ Desenvolver parcerias efetivas

$\checkmark$ Compartilhar informações

$\checkmark$ Expor estratégias a terceiros

$\checkmark$ Apenas gerenciar sem interferir 
Quadro 2: Atributos e subatributos sugeridos para consideração no processo de seleção de um provedor de serviços logísticos.

\begin{tabular}{|c|c|}
\hline ATRIBUTOS & SUBATRIBUTOS \\
\hline $\begin{array}{l}\text { Infra-estrutura de } \\
\text { operações }\end{array}$ & $\begin{array}{l}\text { - Localização dos centros de distribuição } \\
\text { - Área de atuação (cobertura geográfica) } \\
\text { - Área disponível nos centros de distribuição } \\
\text { - Adequação das instalações } \\
\text { - Equipamentos para armazenagem e movimentação de materiais } \\
\text { - Segurança nos centros de distribuição e no transporte } \\
\text { - Parcerias operacionais }\end{array}$ \\
\hline Estabilidade financeira & $\begin{array}{l}\text { - Receita } \\
\text { - Margem de lucro } \\
\text { - Carteira de clientes } \\
\text { - Receita/cliente } \\
\text { - Capacidade de investimento } \\
\text { - Passivo }\end{array}$ \\
\hline $\begin{array}{l}\text { Flexibilidade na prestação } \\
\text { de serviços logísticos }\end{array}$ & $\begin{array}{l}\text { - Gerenciamento de armazém (armazenagem, manuseio de materiais, separação de } \\
\text { pedidos) } \\
\text { - Distribuição de produtos (transportes) } \\
\text { - Controle de estoques } \\
\text { - Gerenciamento de informações logísticas (principalmente status e localização dos } \\
\text { pedidos] } \\
\text { - Logística reversa } \\
\text { - Serviços de consultoria (projetos logísticos] } \\
\text { - Compras } \\
\text { - Reciclagem e destruição }\end{array}$ \\
\hline Credibilidade no mercado & $\begin{array}{l}\text { - Carteira de clientes } \\
\text { - Parcerias logísticas } \\
\text { - Índice anual de renovação de contratos } \\
\text { - Quantidade de novos contratos logísticos efetivados/ano }\end{array}$ \\
\hline Experiência & $\begin{array}{l}\text { - Tempo de atuação no mercado de provedores de serviços logísticos } \\
\text { - Tempo de experiência com o produto ou mercado da empresa contratante } \\
\text { - Carteira de clientes }\end{array}$ \\
\hline Gestão da qualidade & $\begin{array}{l}\text { - Cultura organizacional (valores e missão] } \\
\text { - Certificados de qualidade } \\
\text { - Indicadores de desempenho }\end{array}$ \\
\hline Recursos humanos & $\begin{array}{l}\text { - Qualificação dos funcionários } \\
\text { - Política de desenvolvimento de pessoal }\end{array}$ \\
\hline $\begin{array}{l}\text { Recursos de tecnologia } \\
\text { e informação }\end{array}$ & $\begin{array}{l}\text { - Sistema para gerenciamento integrado de processos [ERP) } \\
\text { - Sistema para gerenciamento do armazém }(W M S \text { ) } \\
\text { - Código de barras } \\
\text { - Sistema para gerenciamento do transporte }[T M S \text { ] } \\
\text { - Troca eletrônica de dados (EDI) } \\
\text { - Disponibilidade de informações pela internet } \\
\text { - Rastreamento por satélite [GPS] } \\
\text { - Sistemas de segurança de informações e contingência de operações } \\
\text { - Parcerias tecnológicas }\end{array}$ \\
\hline $\begin{array}{l}\text { Custos do sistema } \\
\text { logístico }\end{array}$ & $\begin{array}{l}\text { - Custo de capital alocado em estoques na cadeia de suprimentos } \\
\text { - Custos de transportes } \\
\text { - Custos de armazenagem e manuseio de materiais } \\
\text { - Custos de outras atividades logísticas } \\
\text { - Custos para integração tecnológica }\end{array}$ \\
\hline
\end{tabular}


- Avaliar as alternativas de provedores de serviços logísticos e a alternativa interna para a tomada de decisão.

$\mathrm{Na}$ etapa 4 da metodologia, devem ser avaliadas as alternativas para a tomada de decisão. Conforme a Figura 5, esta etapa compreende o envio da RFP (Request for Proposal) para os provedores pré-qualificados, análise das propostas, visita aos provedores, comparação entre as alternativas e negociação com os provedores finalistas.

Figura 3: Atividades que compõem a etapa de identificação das necessidades logísticas da empresa.

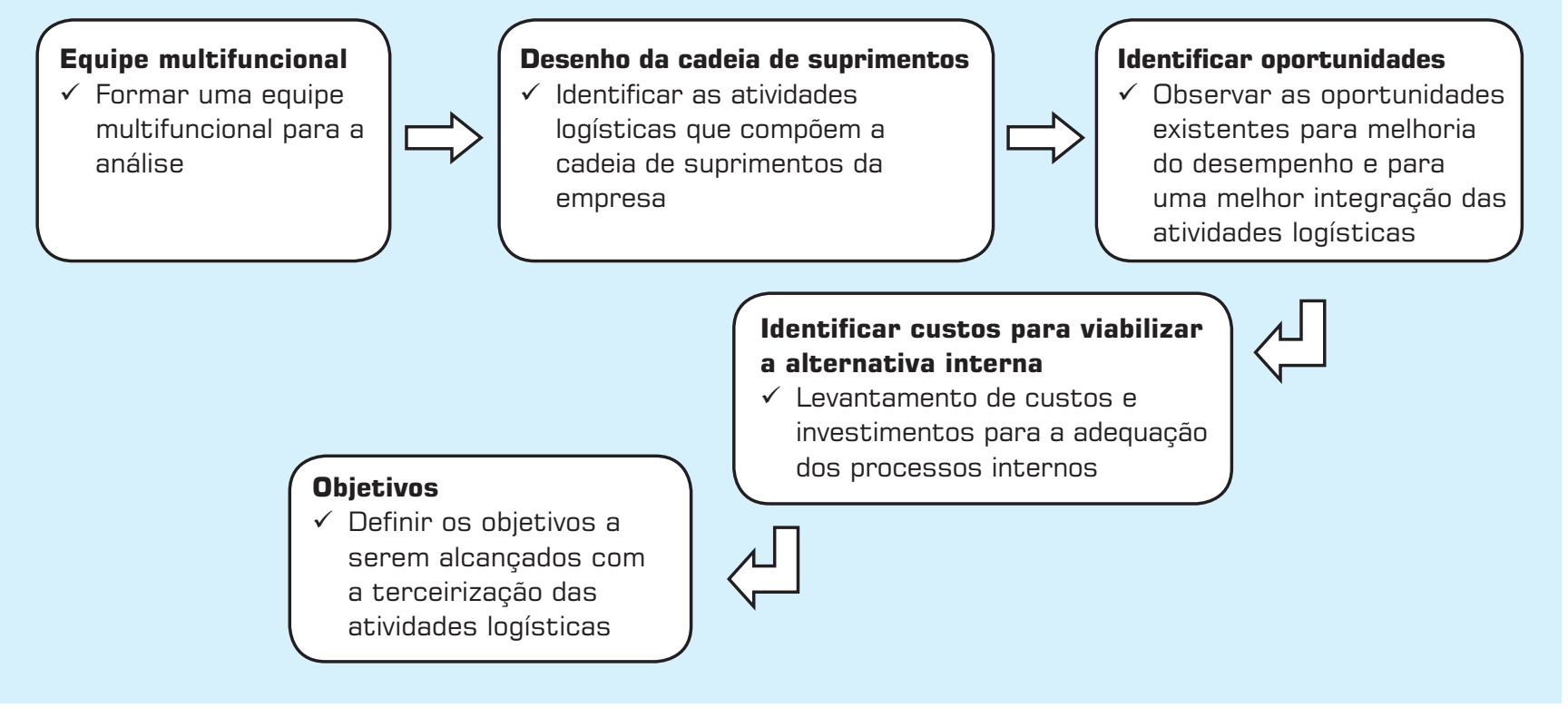

Figura 4: Atividades que compõem a etapa de desenvolvimento das alternativas de provedores de serviços logísticos.

\begin{tabular}{|l|}
\hline Definir os atributos para a \\
avaliação \\
$\checkmark$ Infra-estrutura \\
$\checkmark$ Estabilidade financeira \\
$\checkmark$ Flexibilidade \\
$\checkmark$ Credibilidade no mercado \\
$\checkmark$ Experiência \\
$\checkmark$ Gestão da qualidade \\
$\checkmark$ Recursos humanos \\
$\checkmark$ Recursos de tecnologia \\
$\checkmark$ Custos logísticos \\
\hline
\end{tabular}

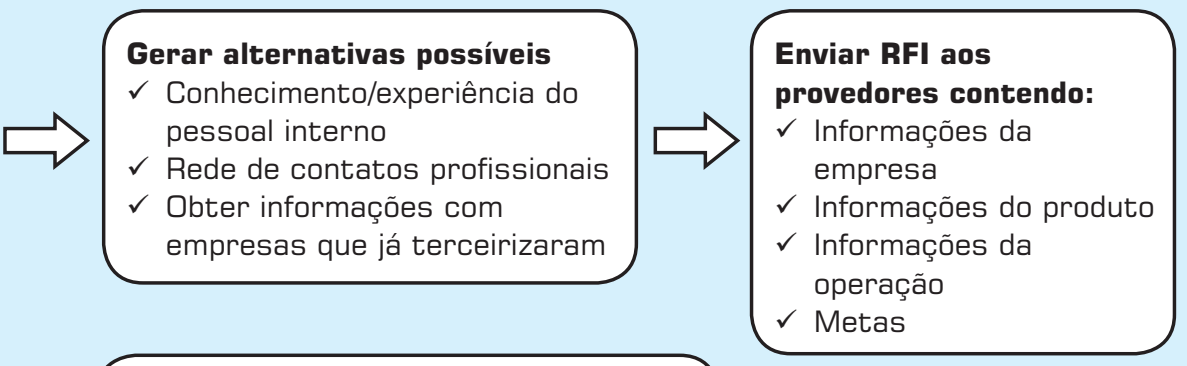

Solicitar na RFI

$\checkmark$ Informações preliminares relacionadas aos atributos definidos anteriormente

$\checkmark$ Referências de outras empresas

\section{Pré-qualificação}

$\checkmark$ Selecionar os provedores de

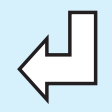

serviços logísticos que atendam atributos mínimos qualificatórios para operar com a empresa 


\section{APLICAC̣ÃO DA METODOLOGIA}

A fim de validar a metodologia proposta e demonstrar o potencial da sua aplicação, a mesma foi aplicada a um estudo de caso que envolveu a avaliação de um processo de terceirização das atividades logísticas para uma grande empresa do setor de eletroeletrônicos, a qual terceirizou grande parte das atividades logísticas de sua cadeia de distribuição.

O levantamento dos dados necessários foi realizado a partir de entrevistas com os responsáveis pelo processo de terceirização logística da empresa, tendo sido identificadas as necessidades da cadeia de suprimentos da empresa e as expectativas com o processo de terceirização, os atributos avaliados no processo decisório, a metodologia utilizada para coleta de dados das alternativas de provedores disponíveis e as dificuldades encontradas na avaliação destas alternativas para a tomada de decisão.

\section{O ambiente de negócios da empresa}

A empresa possui duas unidades industriais, em Manaus e no Vale do Paraíba (SP), além de um centro de distribuição (CD) com cerca de $12.000 \mathrm{~m}^{2}$ de área coberta na unidade do Vale do Paraíba. Esse CD era abastecido pelas duas plantas industriais, e a partir dele os produtos eram distribuídos para praticamente todo o mercado nacional e também para o Exterior, atendendo aproximadamente 1.500 pontos distintos, entre atacadistas/distribuidores, varejistas e alguns grandes consumidores finais.
Em 1998, a empresa decidiu rever e redesenhar todos os processos logísticos em seu CD. Em 1999 foi iniciado o desenvolvimento do projeto de armazém geral para o seu CD. Até aquele ano, a transferência dos produtos da fábrica de Manaus para o CD era realizada através de um processo de venda da matriz (Manaus) para a sua filial (São Paulo). Por se tratar de um processo de venda, havia incidência de PIS e COFINS (3,65\%), e ainda de ICMS, no momento da transferência. Quando ocorria a venda para o cliente final, através da filial localizada no CD em São Paulo, a empresa era tributada novamente em PIS e COFINS (3,65\%), gerando duplicidade no pagamento de impostos. Através de um projeto de planejamento tributário, verificou-se a oportunidade para se evitar esses impostos em duplicidade (PIS e COFINS) e também para a postergação no pagamento de ICMS, caso fosse constituído um armazém geral no seu CD de São Paulo.

A necessidade de rápida implantação desse armazém geral foi o principal motivador para a empresa optar pela terceirização in house de suas atividades logísticas. Como o processo para constituição de um armazém geral leva no mínimo 6 meses, requer inúmeros procedimentos fiscais burocráticos e ainda exige consideráveis alterações nos sistemas utilizados para gerenciamento das operações, a empresa optou por terceirizar suas atividades logísticas. Buscou-se um provedor de serviços logísticos que já dispusesse do regime de armazém geral e tivesse experiência com operações dentro deste regime fiscal.

Figura 5: Atividades que compõem a etapa de avaliação das alternativas para a tomada de decisão.

\section{Enviar RFP solictando:}

$\checkmark$ Projeto logístico elaborado pelo provedor

$\checkmark$ Proposta comercial para as atividades que serão terceirizadas

$\checkmark$ Dados detalhados dos atributos que serão avaliados

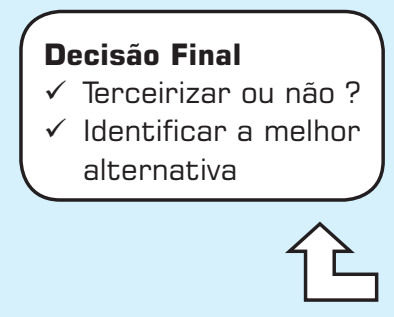

\section{Avaliação e negociação}

$\checkmark$ Análise benefício/custo entre os provedores finalistas e a alternativa interna

$\checkmark$ Negociação com os provedores finalistas

Visitas aos provedores

$\checkmark$ Comprovar capacitações

$\checkmark$ Auditar operações

$\checkmark$ Conversar com dirigentes, funcionários e clientes
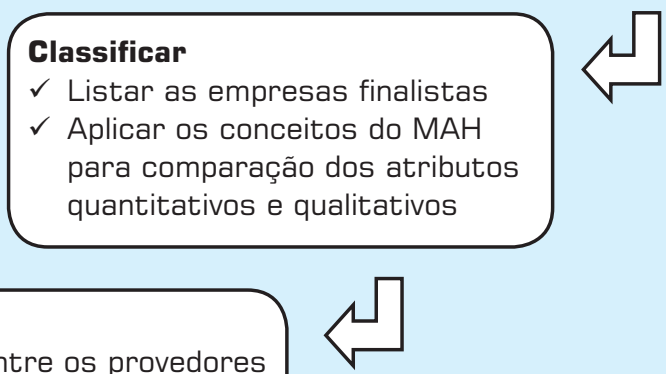
Nas entrevistas realizadas com os tomadores de decisão identificaram-se outros aspectos importantes decorrentes da terceirização, tais como foco da empresa em suas atividades principais, maior flexibilidade nas operações, redução de custos logísticos e transformação de custos fixos em custos variáveis, acesso a novas tecnologias e melhorias em suas operações globais.

Devido à necessidade de rápida implantação do projeto de armazém geral (3 meses), não houve tempo suficiente para a empresa refletir a respeito de todos os aspectos sugeridos para a primeira etapa da metodologia proposta, os quais envolvem a compreensão das oportunidades e os riscos com a terceirização das atividades logísticas.

Mesmo assim, verificou-se que a decisão de terceirização foi facilitada pelo fato de a alta administração já possuir conhecimento adequado dos conceitos e capacitações relacionados a um provedor de serviços logísticos, estar plenamente comprometida com o processo de terceirização, e ter pleno conhecimento das atividades logísticas que seriam terceirizadas, possibilitando assim uma clara definição das metas do provedor de serviços logísticos e um eficaz monitoramento das atividades logísticas após a sua terceirização.

É importante ressaltar que, apesar de o objetivo inicial da empresa com a terceirização de suas atividades logísticas ser a rápida contratação de um provedor que dispusesse do regime de armazém geral, ficando restrita a atuação do mesmo, em um primeiro momento, à armazenagem $\mathrm{e}$ ao manuseio de materiais, esta mantinha como foco de sua estratégia mundial a redução do número de fornecedores de serviços logísticos através da ampliação futura do escopo de atuação do provedor selecionado. Desta forma, a empresa objetivava gerar uma parceria efetiva com um grande provedor, o qual futuramente seria responsável pelo planejamento, integração, gerenciamento e operação de grande parte das atividades logísticas que compunham sua cadeia de suprimentos.

\section{A metodologia utilizada para seleção}

O processo de seleção realizado pela empresa compreendeu as seguintes etapas: formação da equipe multidisciplinar, pré-qualificação dos provedores, processo de licitação junto aos provedores pré-qualificados, determinação dos pesos dos atributos e subatributos e avaliação das alternativas.

Foram observadas algumas diferenças entre a metodologia para seleção proposta neste artigo e aquela utilizada pela empresa para a sua tomada de decisão. As diferenças foram decorrentes, principalmente, da urgência para a finalização do processo de escolha, que não permitiu que a referida em- presa seguisse plenamente todas as etapas propostas.

Inicialmente, observou-se não ter havido tempo suficiente para a empresa refletir a respeito de todos os motivadores, oportunidades e riscos com a terceirização de suas atividades logísticas, sendo alguns destes aspectos identificados apenas após a implementação da operação. É importante salientar que a equipe multidisciplinar reconheceu a importância desta atividade, destacando que algumas dificuldades encontradas durante e após a implantação da operação poderiam ter sido evitadas, caso a empresa tivesse tempo de realizar uma boa análise de todas as oportunidades e riscos com a terceirização de suas atividades logísticas.

Outro aspecto diferente da metodologia apresentada foi o fato das etapas compostas pelo envio da RFI e da RFP terem sido consolidadas em uma única etapa. Diferentemente do apresentado na metodologia, também por problemas de prazo reduzido para a implantação da operação, a empresa não seguiu o procedimento proposto de envio da $R F I$ a diversos provedores, pré-qualificação de alguns provedores e envio da RFP apenas aos provedores pré-qualificados.

\section{provedor de serviços logísticos, de acordo com as suas características e necessidades.}

Desta forma, entende-se que a empresa pode ter perdido a oportunidade de avaliar outras alternativas viáveis a sua operação, restringindo assim a sua tomada de decisão a um grupo restrito de alternativas.

Pôde ser observado também que as principais dificuldades para a empresa estavam na avaliação dos diversos atributos e subatributos, qualitativos e quantitativos, considerados para o processo decisório, como também na comparação das alternativas de provedores com relação a estes atributos e subatributos para a correta tomada de decisão.

A metodologia aplicada pela empresa apresentava características que geravam, em alguns casos, a necessidade de a equipe multidisciplinar refazer parte de seu trabalho de avaliação e distribuição de pesos, como também existiam problemas decorrentes da falta de mecanismos para controle da consistência dos julgamentos efetuados pela equipe multidisciplinar, podendo causar distorções na avaliação dos atributos, subatributos e das alternativas.

Os atributos e subatributos eram avaliados segundo um critério de pontuação. Para determinar os pesos dos atributos e sub-atributos, a empresa utilizou uma técnica na qual a equipe multidisciplinar, através de um processo de consen- 
so de opiniões, deveria distribuir pontos para cada um dos sub-atributos avaliados, sendo que a soma total de todos os pontos dados aos subatributos deveria ser igual a 1.000.

Após a determinação dos pesos de todos os sub-atributos, a equipe multidisciplinar avaliou as diversas alternativas, dando notas de 0 a 10 para cada provedor logístico com relação a cada subatributo avaliado. A nota final de cada provedor com relação a um determinado sub-atributo foi o resultado da média aritmética entre as notas individuais dadas por cada um dos integrantes da equipe multidisciplinar.

A Tabela 1 ilustra a metodologia utilizada pela empresa, onde a pontuação final de cada alternativa é a somatória de todas as notas dadas a esta alternativa, ponderada pelo peso dos diversos subatributos avaliados.

A técnica utilizada pela empresa apresenta basicamente dois problemas principais. O primeiro problema está no fato de que após a equipe multidisciplinar indicar os pontos dados a todos os subatributos a soma dos mesmos pode não atingir 1.000 pontos, fazendo com que a equipe multidisciplinar tenha que refazer todo o trabalho de pontuação. O segundo problema, neste caso considerado como o mais grave, é decorrente do fato de não existirem mecanismos para controle da consistência dos julgamentos efetuados pela equipe multidisciplinar, podendo assim ocorrer distorções na avaliação dos atributos, subatributos e das alternativas.
Estas distorções decorrem do fato de a equipe multidisciplinar preocupar-se apenas em atender as premissas da técnica utilizada (por exemplo, a somatória dos pontos dados aos diversos subatributos deve ser igual a 1.000), deixando em segundo plano a consistência de seus julgamentos. Por exemplo, na Tabela 1, embora o subatributo F tenha recebido 20 pontos, o subatributo L tenha recebido 40 pontos e o subatributo J tenha recebido 80 pontos, isto não significa necessariamente que a equipe multidisciplinar tenha convicção que para a tomada de decisão o subatributo L seja duas vezes mais importante que $\mathrm{F}$, e o subatributo $\mathrm{J}$ seja quatro vezes mais importante que $\mathrm{F}$ e duas vezes mais importante que L. Verificou-se que os dados foram inseridos na tabela sem grandes questionamentos se os mesmos representam fielmente os julgamentos da equipe multidisciplinar.

A fim de evitar as distorções acima, foi proposta à empresa a aplicação dos conceitos do MAH para auxílio à determinação dos pesos dos atributos e subatributos, assim como para a avaliação das alternativas disponíveis.

\section{Os atributos avaliados no processo decisório}

Para a avaliação das alternativas de provedores participantes do processo de licitação, foram considerados atributos quantitativos e atributos qualitativos. Os atributos e respectivos subatributos utilizados pela empresa para a comparação das alternativas estão apresentados no Quadro 3 , sendo também indicadas as siglas que serão utilizadas no

Tabela 1: Determinação do peso dos subatributos e classificação das alternativas.

\begin{tabular}{|c|c|c|c|c|c|c|c|c|c|}
\hline \multirow{2}{*}{ SUB-ATRIBUTO } & \multirow{2}{*}{ PONTOS } & \multicolumn{2}{|c|}{ ALTERNATIVA 1} & \multicolumn{2}{|c|}{ ALTERNATIVA 2} & \multicolumn{2}{|c|}{ ALTERNATIVA 3} & \multicolumn{2}{|c|}{ ALTERNATIVA 4} \\
\hline & & NOTA & TOTAL & NOTA & TOTAL & NOTA & TOTAL & NOTA & TOTAL \\
\hline A & 50 & 5 & 25 & 4 & 20 & 5 & 25 & 10 & 50 \\
\hline $\mathrm{B}$ & 100 & 6 & 60 & 10 & 100 & 6 & 60 & 7 & 70 \\
\hline C & 30 & 8 & 24 & 7 & 21 & 8 & 24 & 7 & 21 \\
\hline $\mathrm{D}$ & 80 & 7 & 56 & 7 & 56 & 7 & 56 & 9 & 72 \\
\hline$E$ & 130 & 10 & 130 & 9 & 117 & 10 & 130 & 0 & 0 \\
\hline $\mathrm{F}$ & 20 & 10 & 20 & 0 & 0 & 10 & 20 & 7 & 14 \\
\hline G & 45 & 0 & 0 & 10 & 45 & 0 & 0 & 5 & 22,5 \\
\hline $\mathrm{H}$ & 100 & 4 & 40 & 10 & 100 & 7 & 70 & 4 & 40 \\
\hline 1 & 100 & 9 & 90 & 7 & 70 & 10 & 100 & 9 & 90 \\
\hline$J$ & 80 & 10 & 80 & 7 & 56 & 10 & 80 & 10 & 80 \\
\hline $\mathrm{K}$ & 50 & 7 & 35 & 9 & 45 & 0 & 0 & 7 & 35 \\
\hline $\mathrm{L}$ & 40 & 0 & 0 & 0 & 0 & 4 & 16 & 0 & 0 \\
\hline $\mathrm{M}$ & 75 & 8 & 60 & 7 & 52,5 & 9 & 67,5 & 8 & 60 \\
\hline $\mathrm{N}$ & 30 & 9 & 27 & 5 & 15 & 10 & 30 & 9 & 27 \\
\hline \multirow[t]{2}{*}{0} & 70 & 10 & 70 & 9 & 63 & 5 & 35 & 10 & 70 \\
\hline & 1000 & & 717 & & 760,5 & & 713,5 & & 651,5 \\
\hline
\end{tabular}


momento da aplicação dos conceitos do MAH a este problema decisório através da inserção dos atributos, subatributos e alternativas no software Expert Choice ${ }^{2}$.

\section{A aplicação do MAH}

A equipe multidisciplinar da empresa foi convidada a aplicar os conceitos do MAH, tanto para a etapa de determinação dos pesos dos atributos e subatributos, como também para a comparação das alternativas que participaram do processo de licitação.

Os conceitos do MAH foram aplicados com o auxílio do software Expert Choice, o qual possibilita diversas simula- ções com bastante eficiência e praticidade, além de apresentar os resultados em formas gráficas de fácil interpretação.

A Figura 6 representa a tela do software Expert Choice contendo os elementos básicos da estrutura hierárquica completa, onde são apresentados no primeiro nível o objetivo principal, no segundo nível os atributos, no terceiro nível os subatributos utilizados para mensurar cada atributo e no quarto nível, as alternativas avaliadas.

Na segunda etapa de aplicação do MAH, obtêm-se os julgamentos entre os atributos de decisão. O princípio básico da análise de decisão através do MAH é atribuir valores de julgamentos relativos por comparações dos elementos dois a

Quadro 3: Atributos e subatributos utilizados pela empresa para avaliação das alternativas de provedores de serviços logísticos.

\begin{tabular}{|c|c|}
\hline ATRIBUTO & SUBATRIBUTOS \\
\hline Experiência (EXPERIEN) & $\begin{array}{l}\text { Tempo de atuação no mercado nacional de provedores de serviços logísticos } \\
\text { (MERCNAC) } \\
\text { Tempo de experiência com operações in house (IN HOUSE) Carteira de clientes } \\
\text { similares a empresa (CARTSIM) }\end{array}$ \\
\hline $\begin{array}{l}\text { Flexibilidade na prestação de } \\
\text { serviços logísticos (FLEXIB) }\end{array}$ & $\begin{array}{l}\text { Armazenagem e manuseio de materiais (ARMAZMAN) } \\
\text { Controle de estoques (CONTREST) } \\
\text { Gerenciamento de informações logísticas (GERINFO) } \\
\text { Gerenciamento de transporte nacional (TRANSNAC) } \\
\text { Gerenciamento de transporte internacional (TRANSINT) } \\
\text { Logística reversa (LOGREV) } \\
\text { Reciclagem (RECICL) }\end{array}$ \\
\hline Estabilidade financeira (ESTAB) & $\begin{array}{l}\text { Receita total do provedor (RECTOT) } \\
\text { Receita por cliente (RECCLI) } \\
\text { Representatividade da receita do maior cliente (REC>CLI) } \\
\text { Capacidade de investimento (CAPINVES) } \\
\text { Passivo (PASSIVO) }\end{array}$ \\
\hline $\begin{array}{l}\text { Potencial para parcerias } \\
\text { estratégicas (PARCESTR) }\end{array}$ & $\begin{array}{l}\text { Carteira de clientes (CARTCLI) } \\
\text { Parcerias logísticas (PARCLOG) } \\
\text { Índice anual de renovação de contratos (INDRENOV) } \\
\text { Capacitação da equipe de relacionamento (EQUIPREL) }\end{array}$ \\
\hline $\begin{array}{l}\text { Gestão da qualidade dos } \\
\text { processos operacionais } \\
\text { [GESTQUAL] }\end{array}$ & $\begin{array}{l}\text { Programa de gestão da qualidade (PROGRAM) } \\
\text { Existência de área específica voltada para gestão da qualidade (AREAESP) } \\
\text { Certificados de gestão da qualidade (CERTIFIC) }\end{array}$ \\
\hline $\begin{array}{l}\text { Política de recursos humanos } \\
\text { (RECHUM) }\end{array}$ & $\begin{array}{l}\text { Tipo de relação trabalhista (RELTRAB) } \\
\text { Qualificação dos funcionários (QUALFUNC) } \\
\text { Turn-over (TURNOVER) } \\
\text { Política de desenvolvimento de pessoal (POLITDES) }\end{array}$ \\
\hline Tecnologia aplicada (TECNOLOG) & $\begin{array}{l}\text { ERP (ERP) } \\
\text { WMS (WMS) } \\
\text { TMS (TMS) } \\
\text { Código de barras e radiofreqüência (CODBARR) } \\
\text { Monitoramento de operações pela internet (INTERNET) } \\
\text { Planos futuros para investimento em tecnologia (INVESTEC) }\end{array}$ \\
\hline Custos logísticos (CUSTOS) & $\begin{array}{l}\text { Custo total do sistema logístico (CUSTLOG) } \\
\text { Planos para redução de custos (PLANRED) }\end{array}$ \\
\hline
\end{tabular}


dois. Utiliza-se neste ponto a escala apresentada anteriormente no Quadro 1, para pontuar as preferências dos decisores nas comparações relativas considerando cada par de atributos.

Vale notar que no software Expert Choice os dados são apresentados em uma matriz incompleta, isto é, são representados apenas os julgamentos dos pares acima da diagonal principal da matriz, dada a simetria das comparações.

A equipe multidisciplinar da empresa comparou cada par sob o ponto de vista de um determinado atributo do nível hierárquico superior. Por exemplo, os sete atributos selecionados para o nível 1 (EXPERIEN, FLEXIB, ESTAB, PARCESTR, GESTQUAL, RECHUM, TECNOLOG) foram comparados aos pares, com o intuito de se verificar o quanto contribuem para o objetivo principal, que é a seleção de um provedor de serviços logísticos.

Outro ponto importante é que o software não trabalha com representações fracionárias. Portanto, como no caso da última célula abaixo à direita da Figura 7, quando o elemento representado na coluna tem maior representatividade do que o elemento representado na linha, o julgamento estará grafado em destaque. Por exemplo, na comparação entre FLEXIB e ESTAB, mostrada na Figura 7, a nota 3 é favorável a ESTAB, pois está em destaque.
Segundo os julgamentos observados na Figura 7 e os resultados apresentados na Figura 8, observa-se que a equipe multidisciplinar considerou o atributo experiência como o mais relevante para a seleção do provedor de serviços logísticos, seguida pelos atributos estabilidade financeira e potencial para parcerias estratégicas. As empresas procuram provedores que agreguem valor aos seus processos com base na experiência e expertise prévios, reduzindo assim o risco de ineficiências ocasionadas pela falta de experiência de um provedor iniciante.

A estabilidade financeira e o potencial para parcerias estratégicas também foram altamente valorizados pela equipe multidisciplinar, uma vez que em uma parceria que tende a ser de longo prazo, caracterizada por elevados custos de implementação e de reversão.

Desta forma, puderam ser determinadas também as Matrizes de Comparações Paritárias para o 2onivel de subatributos. Neste caso cada atributo será avaliado com relação aos diversos subatributos que o identificam, sendo determinados os pesos de cada subatributo na mensuração do atributo do nível imediatamente superior.

As alternativas também foram comparadas segundo os diversos atributos e subatributos importantes para a tomada

Figura 6: Elementos básicos da estrutura hierárquica do MAH aplicada ao problema da seleção de um provedor de serviços logísticos.

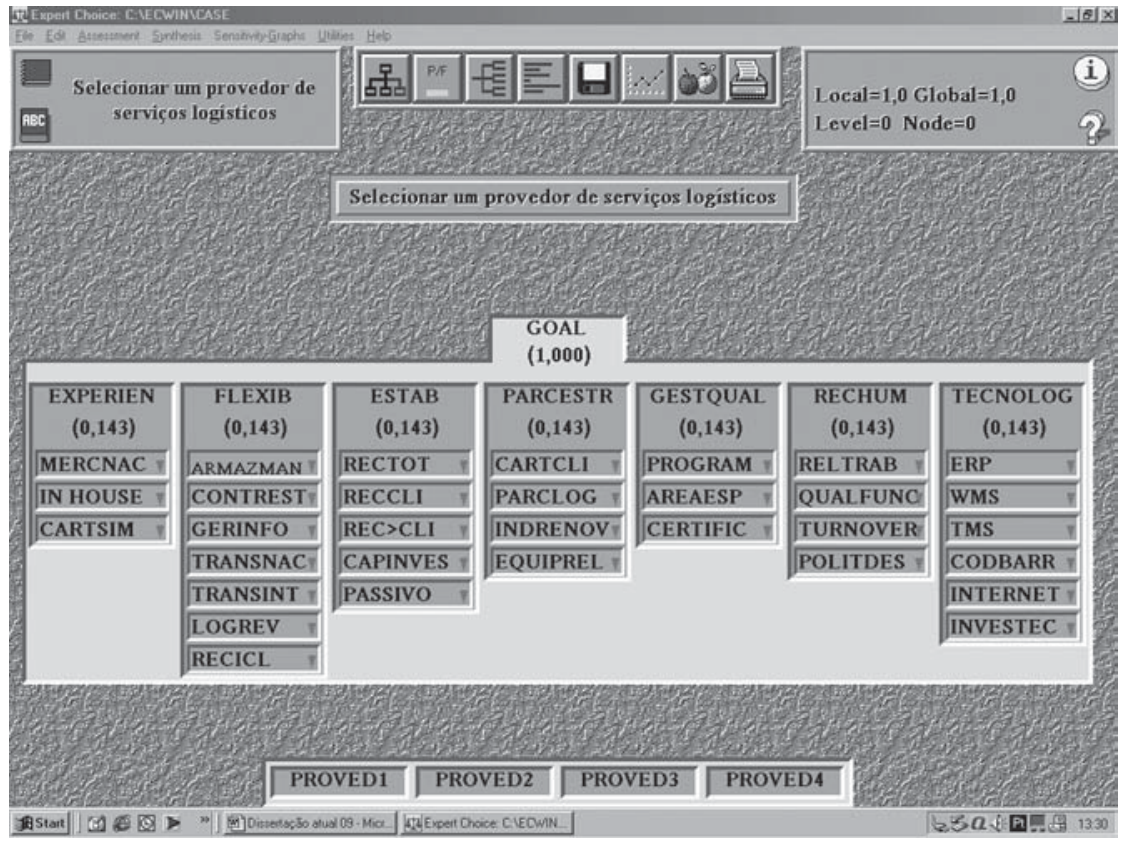


Figura 7: MCP para o 1ํ nível dos atributos.

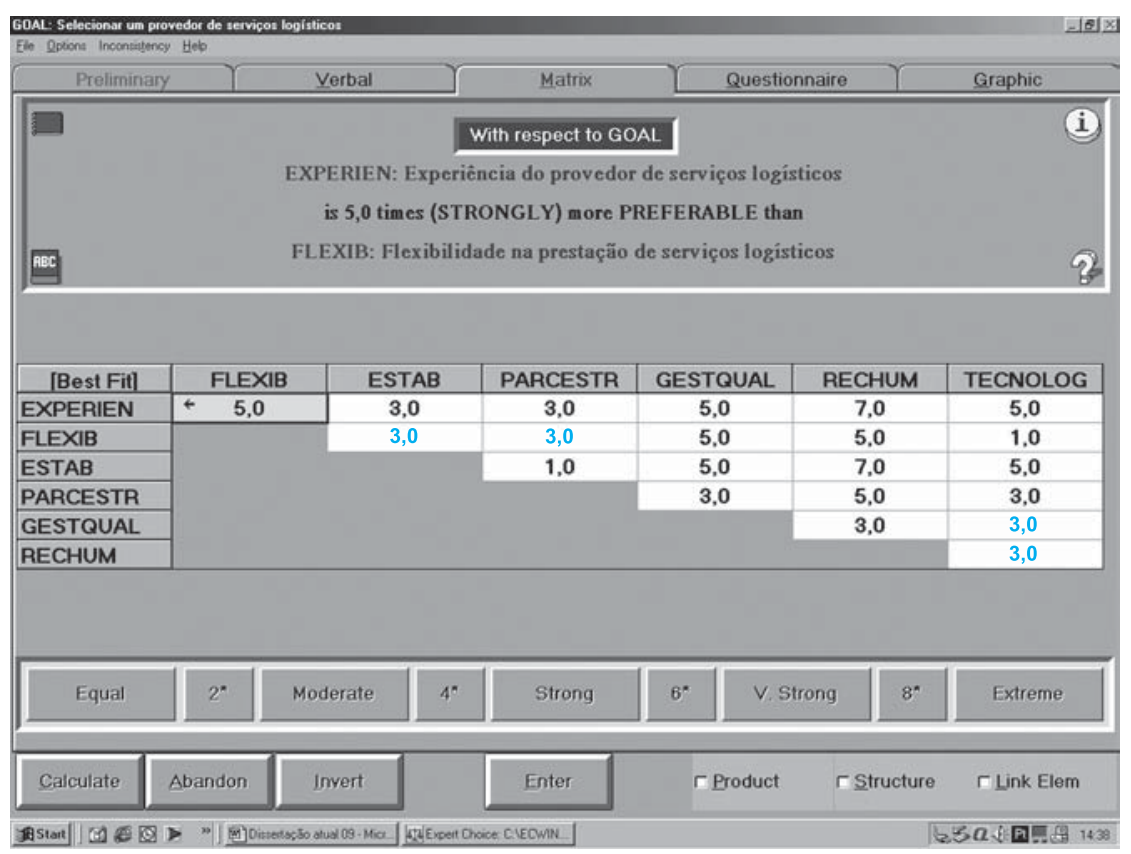

Figura 8: Resultado das comparações paritárias para o $1^{0}$ nível dos atributos.

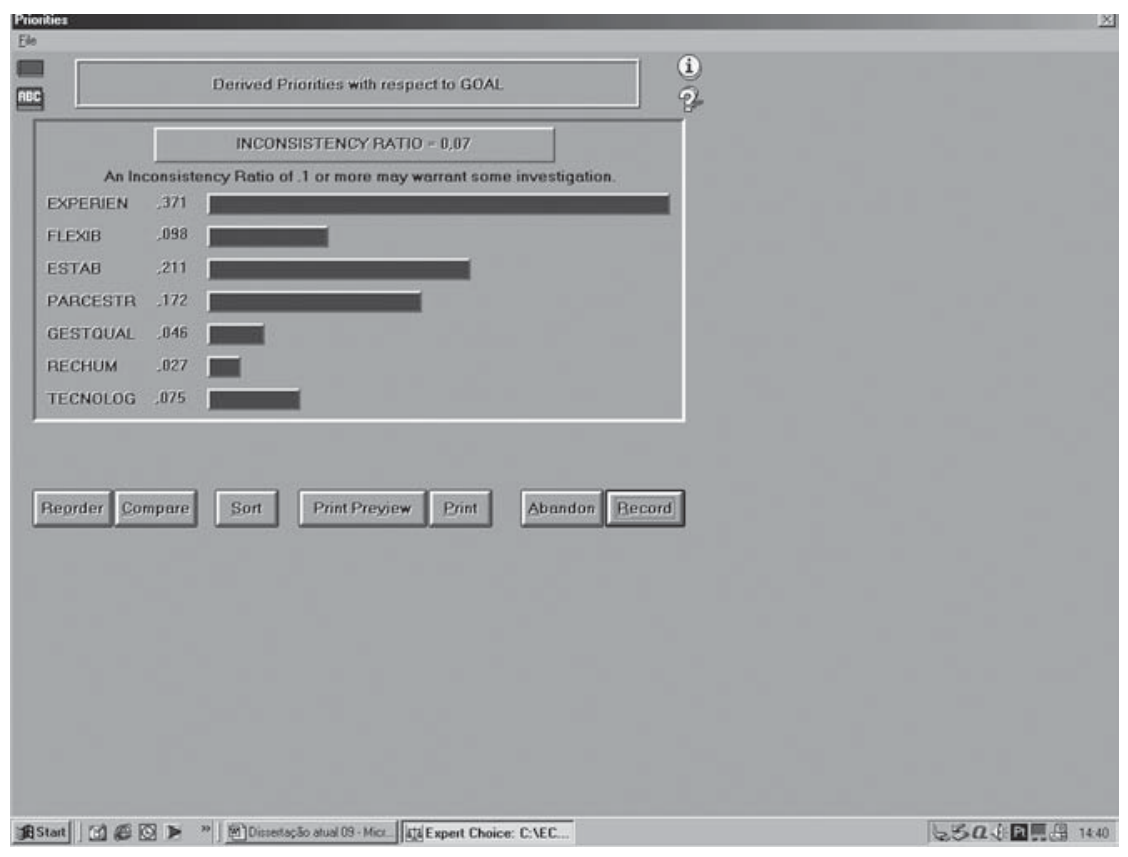


de decisão. A partir destas comparações paritárias e consolidação dos julgamentos pôde-se concluir qual alternativa representava melhor benefício para a empresa em questão.

Após a análise e a consolidação dos julgamentos para todos os atributos e subatributos considerados no processo decisório, e de acordo com os resultados apresentados na Figura 9, o provedor de serviços logísticos 2 é a alternativa apontada como a mais indicada para a empresa contratante.

Para a tomada de decisão, conforme proposto na metodologia, deve-se ainda considerar o atributo custos totais do sistema logístico, realizando-se a análise benefício/custo de cada uma das alternativas disponíveis.
Os custos totais do sistema logístico, para cada uma das alternativas, devem ser normalizados, conforme apresentado na Tabela 2. A análise benefício/custo para cada uma das alternativas é apresentada na Tabela 3.

Embora os custos apresentados pelo provedor de serviços logísticos 2 (PROVED 02) sejam superiores aos demais, este apresenta-se como a melhor alternativa após a análise benefício/custo, sendo, portanto, a alternativa mais indicada para a empresa.

É importante ressaltar que a análise de decisão através do MAH não objetiva substituir o processo de tomada de decisão e negociação dos executivos da empresa, mas apenas auxiliá-los em suas tomadas de decisão mais complexas.

Figura 9: Consolidação dos julgamentos com relação à seleção do provedor de serviços logísticos.

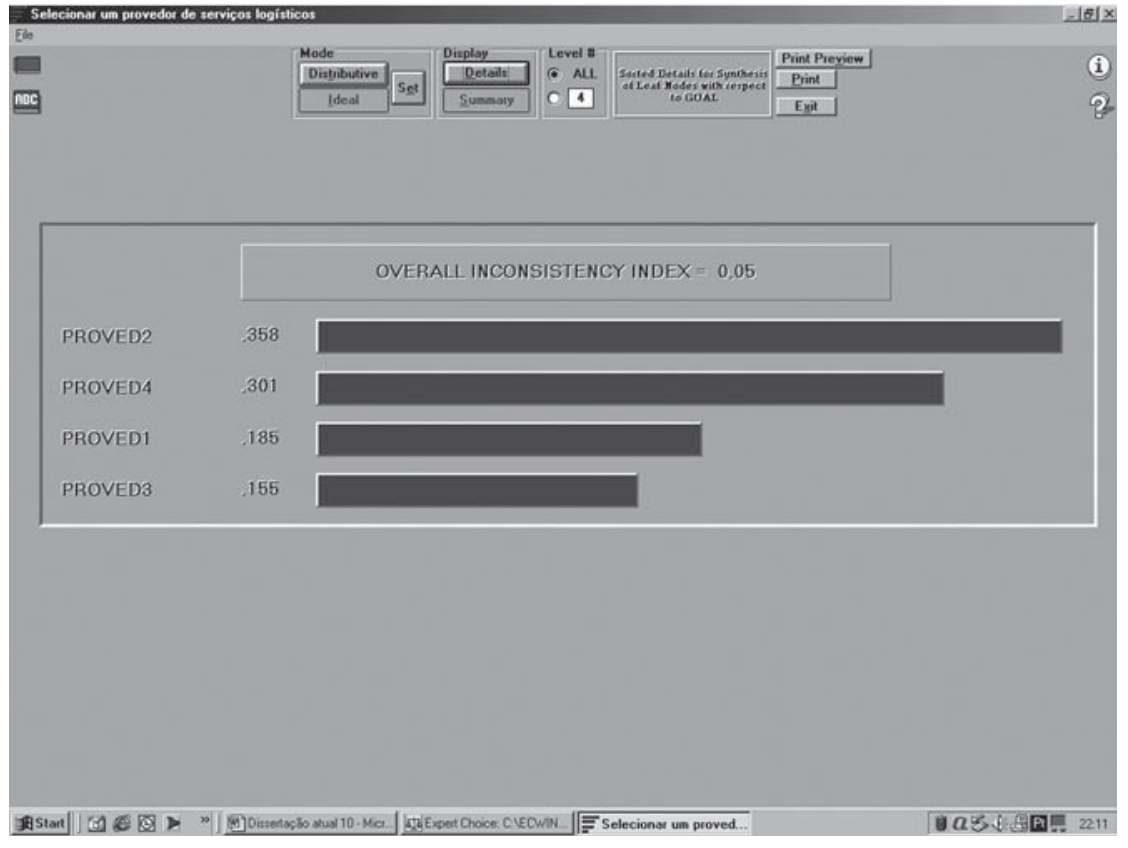

Tabela 2: Normalização dos custos totais do sistema logístico.

\begin{tabular}{|c|c|c|c|}
\hline ALTERNATIVAS & CUSTO TOTAL PROPOSTO & CUSTO NORMALIZADO & CUSTO NORMALIZADO \\
\hline PROVED 01 & $\mathrm{R} \$ 840.000$ & $840.000 / 3.405 .000$ & 0,247 \\
\hline PROVED 02 & $\mathrm{R} \$ 890.000$ & $890.000 / 3.405 .000$ & 0,261 \\
\hline PROVED 03 & $\mathrm{R} \$ 855.000$ & $855.000 / 3.405 .000$ & 0,251 \\
\hline PROVED 04 & $\mathrm{R} \$ 820.000$ & $820.000 / 3.405 .000$ & 0,241 \\
\cline { 2 - 4 } & \multicolumn{2}{|c|}{$\mathbf{R} \mathbf{3 . 4 0 5 . 0 0 0}$} & $\mathbf{1 , 0 0 0}$ \\
\cline { 2 - 4 } & & &
\end{tabular}


Tabela 3: Análise Benefício/Custo para cada uma das alternativas.

\begin{tabular}{|c|c|c|c|}
\hline ALTERNATIVAS & BENEFícIO & CUSTO NORMALIZADO & BENEFÍcIO/CUSTO \\
\hline PROVED 01 & 0,185 & 0,247 & 0,749 \\
\hline PROVED 02 & 0,358 & 0,261 & 1,372 \\
\hline PROVED 03 & 0,155 & 0,251 & 0,618 \\
\hline PROVED 04 & 0,301 & 0,241 & 1,249 \\
\cline { 2 - 4 } & $\mathbf{1 , 0 0 0}$ & $\mathbf{1 , 0 0 0}$ & \multicolumn{2}{|c}{} \\
\cline { 2 - 4 } & &
\end{tabular}

Sendo assim, uma prática comum a algumas empresas, e também sugerida na metodologia, é que após a obtenção da relação benefício/custo, para todas as alternativas analisadas, deva ser realizada uma nova análise dos custos totais do sistema logístico propostos pelos provedores de serviços logísticos finalistas do processo de seleção. Esta nova fase inclui etapas de negociação comercial de valores com os provedores de serviços logísticos, o que pode modificar os custos inicialmente propostos, e, assim, alterar ou ratificar a ordem das alternativas após uma primeira análise com o MAH.

A pequena diferença nos resultados entre os provedores 2 e 4 pode levar a empresa a optar pela contratação do provedor 4 , uma vez que o seu custo é quase $8 \%$ inferior ao do provedor 2, e a diferença dos julgamentos em relação aos benefícios não foi muito significativa.

Desta forma, ficam evidenciadas as vantagens da aplicação do MAH para a estruturação do problema, proporcionando um embasamento quantitativo mais consistente, uma maior credibilidade, como também uma melhor sistematização e documentação de todo o processo decisório.

\section{CONCLUSÕES}

Em linhas gerais, a metodologia desenvolvida tem por objetivo auxiliar as empresas situadas em três diferentes níveis. No primeiro nível, no qual ainda estão localizadas a maior parte das empresas, estão aquelas que não enxergam as oportunidades e riscos com a terceirização de suas atividades logísticas, pois não conseguem compreender, principalmente, os motivadores que têm contribuído para o desenvolvimento do mercado de provedores de serviços logísticos.

No segundo nível estão as empresas que conseguem compreender as oportunidades e riscos com a terceirização de suas atividades logísticas, mas não são capazes de identificar os atributos mais importantes para este processo decisório.

Já o terceiro nível é formado por empresas que compreendem as oportunidades e riscos com a terceirização, conseguem identificar os principais atributos para o processo decisório, mas apresentam dificuldades na comparação das alternativas disponíveis com relação aos diversos atributos importantes para a tomada de decisão.

Assim, o desenvolvimento da metodologia e a aplicação do MAH visam ampliar a compreensão das empresas situadas nos diferentes níveis e auxiliá-las na avaliação da oportunidade de terceirização de suas atividades logísticas.

Uma outra contribuição da metodologia, objetivando atender uma exigência de processos decisórios importantes realizados em grandes empresas, é o fato de ser gerada toda uma documentação que embase a decisão tomada pela empresa contratante (RFI, RFP, hierarquia de atributos e subatributos, julgamentos paritários, consolidação de prioridades), documentação esta que se torna ainda mais importante quando a decisão não é realizada a favor da alternativa de menor custo.

Cabe notar que esta é uma vantagem importante da metodologia proposta, e também decorrente da utilização do MAH, uma vez que ao longo das etapas de aplicação da metodologia é gerada uma extensa documentação de todo o processo decisório, a qual ficará disponível para ser analisada em prováveis auditorias realizadas na empresa. 


\section{- Referências Bibliográficas}

ACKERMAN, K. B. Pitfalls in logistics partnerships. International Journal of Physical Distribution and Logistics Management, $\mathrm{v}$. 26, n. 3, p. 35-37, 1996.

BALLOU, R. H. Business logistics management. 4th ed. New Jersey: Prentice-Hall, 1998.

BOWERSOX, D. J. e CLOSS, D. J. Logistical management: the integrated supply chain process. McGraw Hill, 1996.

BOWMAN, R. J. A guide to logistics outsourcing. Distribution Review, v. 96 , n. 11, p. $34-42,1997$.

BOYSON, S.; CORSI, T.; DRESNER, M. e RABINOVICH. Managing effective third party logistics relationships: what does it take? Journal of Business Logistics, v. 20, n. 1 , p. $73-100,1999$.
CAIXETA-FILHO, J. V. e MARTINS, R. S. Gestão logística do transporte de cargas. São Paulo: Editora Atlas, 2001.

FLEURY, P. F. Logística empresarial: a perspectiva brasileira. São Paulo: Editora Atlas, 2000

GULISANO, V. Third party failures: Why keep it secret? Transportation $\&$ Distribution Review, Set., p. 77, 1997.

HOFFMAN, K. C. What is a 4PL anyway? Logistics Management \& Distribution Report, Nov., 2000.

IAÑEZ, M. M. Uma contribuição ao processo decisório de terceirização das atividades logísticas. Dissertação de Mestrado, Departamento de Engenharia de Transportes da Escola Politécnica da Universidade de São Paulo, 2002.

LIEB, R. C. e MILLER, J. Growth spurt. Logistics Management \& Distribution Report, Nov. 2000.

LIEB, R. C.; MILLER, R. A.; VAN WASSENHOVE, L. N. Third party logistics services: a comparasion of experienced American and European manufactures. International Journal of Physical Distribution and Logistics Management, v. 23, n. 6, p. 41, 1993.

LIEB, R. C.; RANDALL, H. L. A comparison use of third party logistics services by large American manufactures - 1991,
1994 e 1995. Journal of Business Logistics, v. 17 , n. 1 , p. 306,1996

LYNCH, C. F. Logistics outsourcing - A management guide. Council of Logistics Management, Oak Brook, 2000.

SAATY, T. L. The analytic hierarchy process - planning, priority setting, resource allocation. New York: McGrawHill, 1980.

SINK, H. L. e LANGLEY, C. J. A managerial framework for the acquisition of third party logistics services. Journal of Business Logistics, v. 18, n. 2, p. 163-189, 1997.

VINCKE, P. Multicriteria decision-aid. New York: John Wiley \& Sons Ltda., 1992.

- Sobre o autor

\section{Maurício Mengai Iañez}

Engenheiro Civil pela Escola Politécnica da Universidade de São Paulo.

Mestre em Engenharia de Transportes pela Escola Politécnica da Universidade de São Paulo, tendo desenvolvido dissertação com o tema: "Uma Contribuição ao Processo Decisório de Terceirização das Atividades Logísticas".

End.: Rua Carlos Weber, 601 Bl C, Ap 51 - Lapa - CEP 05303-000 - São Paulo - SP

Tel.: (11) 2179-5630 (com.) (11) 9572-9151 (cel.)

E-mail:mianez@hotmail.com

\section{Cláudio Barbieri da Cunha}

Engenheiro Civil, Mestrado e Doutorado em Engenharia de Transportes pela Escola Politécnica da Universidade de São Paulo (EPUSP). Pós-Doutorado no Department of Industrial and Systems Engineering da Universidade da Flórida. Professor Associado no Departamento de Engenharia de Transportes da EPUSP. Coordenador do Programa de Pós-Graduação em Engenharia de Transportes desde 2004. De 1986 a 1997 foi Pesquisador do IPT - Instituto de Pesquisas Tecnológicas do Estado de São Paulo, nas divisões de Economia e Engenharia de Sistemas e de Tecnologia de Transportes, tendo exercido o cargo de Chefe do Agrupamento de Logística e Transportes.

Suas áreas de interesse incluem Logística, Planejamento e Operação de Transportes, Modelagem Matemática e Desenvolvimento de Algoritmos para Problemas de Logística e Transportes.

End.: Caixa Postal 61548 - CEP 05424-970 - São Paulo - SP

Tel.: (11) 3091-5732 (com) Fax: (11) 3091-5716

E-mail: cbcunha@usp.br 